$\angle$ Research Square

\title{
A study on mental health status among the staff in a designated hospital for COVID- 19
}

\author{
Bangfang Wang \\ Shanghai Public Health Clinical Center \\ Jianjun Sun \\ Shanghai Public Health Clinical Center \\ Feng Gao \\ Shanghai Public Health Clinical Center \\ Jun Chen \\ Shanghai Public Health Clinical Center \\ Lei Shi \\ Shanghai Public Health Clinical Center \\ Lanying Li \\ Shanghai Public Health Clinical Center \\ Yongjun Tang \\ Shanghai Public Health Clinical Center \\ Kun Wang \\ The Second People's Hospital of Lu'an \\ Hongzhou Lu ( $\square$ luhongzhou@fudan.edu.cn) \\ Shanghai Public Health Clinical Center Affiliated to Fudan University Shanghai, 201508
}

\section{Research article}

Keywords: COVID-19, designated hospital, staff, depression, panic disorder

Posted Date: April 30th, 2020

DOI: https://doi.org/10.21203/rs.3.rs-23224/v1

License: (c) (i) This work is licensed under a Creative Commons Attribution 4.0 International License. Read Full License 


\section{Abstract}

Background: We investigate the mental health status of all the staff members who worked for the designated hospital during the initial stage of COVID-19, so as to understand the severity of mental health problems, and analyze the risk factors.

Methods: Through the patients health questionnaire-9(PHQ-9) and panic disorder severity scales(PDSS), we surveyed the status of depression and panic disorder of the staff who participated in the prevention and treatment of COVID-19 in designated hospital in the early stage of epidemic. The data is described by the number of cases (percentage), median and interquartile range. The chi square test was used for categorical variables and the rank sum test was used for continuous variables. The risk factors of severe depression or panic disorder were analyzed by binary logistic regression test.

Results: Totally 702 questionnaires were sent out and 694(98.9\%) was received and qualified, the median score of PHQ-9 among all the staff was 1 (IQR,0-4), 143(20.6\%) of them had depression, 39 (5.6\%) had serious depression; the median score of PDSS was 2 (IQR,0-5), 81 (11.7\%) of them had panic disorder and 47(6.7\%) of them had severe panic disorder; Among the people in different work lines, the first-line staff scored the highest: PHQ9 score was 4 (0-8); PDSS score was 4 (1-9), which were significantly higher than the second-line and third-line staff (P<0.001). Multivariate logistic regression analysis showed that the adjusted risk of severe depression in first-line staff was 6.63 fold $(P<0.001)$; the risk of severe panic disorder was 2.62 fold $(P=0.003)$ higher than that of non-first line group.

Conclusions: Many staff in the designated hospital for COVID-19 have mental health problems. Among them, first-line workers are a high-risk group with severe depression and panic disorder, and further psychological intervention is needed for them.

\section{Background}

The novel coronavirus pneumonia (NCP) is a pneumonia caused by the severe acute respiratory syndrome coronavirus 2(SARS-CoV-2)[1]. It was firstly reported in Wuhan, Hubei province in December 2019[2]. Then the name of novel coronavirus pneumonia was revised to Coronavirus Disease 2019(COVID-19) by WHO[3]. The epidemic is characterized by human to human transmission[4], with high infectivity during incubation[5], so the prevention and control of the epidemic is facing more challenges[6]. At this stage, the global spread of COVID-19 continues to grow, and the full extent and severity of this outbreak remains to be seen[7]. Under this epidemic, health care workers are striving to fight for the COVID-19 and the epidemic could cause a parallel epidemic of fear, anxiety, and depression[8]. During the period of SARS in 2003, the mental health of many medical workers who participated in the control of coronavirus infection was affected[9-11]. As the total number of people infected by COVID-19 currently far exceeds those stricken by the 2003 SARS-CoV epidemic[12]. Since the outbreak of the COVID-19 epidemic, there have been some mental health research reports[12,13], mainly focused on the front-line medical staff and general public. However, COVID-19 is often admitted in designated hospitals, consequently, a number of medical care giver in the hospital and medical personnel are involved in the treatment, including laboratory technician, scientific researcher, administrator, and logistic service supporter. The mental health of all the staff members may be affected in the epidemic, but the research of this aspect is scarce.

Shanghai public health clinical center, as a designated medical center for the treatment of COVID-19 in Shanghai municipality, the medical staff need to contact the confirmed patients directly or indirectly, which may cause a series of psychological state changes. This study will investigate the mental health status of all the staff members who worked for the center during the initial stage of COVID-19, so as to understand the mental health problems such as depression and panic disorder, and analyze the risk factors, so as to help to make target intervention strategies.

\section{Methods}

\section{Objectives}

From January 15 to February 10, 2020, a total of 702 people who worked as physician, nurse, laboratory technician, scientific researcher, administrator, logistics service personnel in our hospital participated in this survey. The survey was conducted from February 8 to February 10 , and each questionnaire was completed by the participant within 10-15 minutes. All subjects provided written informed consent(electronic version) prior to the initiation of study procedures.

\section{Questionnaires}

According to patients health questionnaire-9(PHQ-9) for depression self-assessment scale and panic disorder severity scale Chinese version(PDSSCV) for panic disorder, the questionnaire of depression and panic disorder of medical staff in designated hospital of COVID-19 was adapted by mental health professionals. Both PHQ-9 and PDSS-CV are valid and reliable in Chinese population[14,15]. The contents of the questionnaire include: (1) basic characteristics of the staff, including occupations(physician, nurse, laboratory technician, scientific researcher, administrator, logistics service supporter), gender, age (18-30, 31-40, 41-50, or $>50$ years), working years $(0-5,6-10,11-15$, or $>16$ years), educational level ( $\leq$ undergraduate or $\geq$ postgraduate), technical title (junior, intermediate, or senior). The different technical titles of respondents refer to the professional titles certificated by our hospital. (2) PHQ-9 self rating depression scale questions (comprising 9 items; range, 0-27); and (3) PDSS 
panic disorder severity scale questions (comprising 7 domains; range, $0-28$ ). According to the criteria of PHQ-9, the score is $0-4$ for normal, 5-9 for mild depression, 10-14 for moderate depression, and more than 15 for severe depression. According to the criteria of PDSS, 0-3 is normal; 3-7 is borderline; 8-10 is slightly panic; $11-15$ is moderately panic and more than 16 is markedly panic. Participants with PHQ-9 score more than 10 points, or PDSS score more than 11 points, we defined it as severe status of depression[13] or panic disorder[16]. Full-time staff in the department of hospital infection and control conduct questionnaire surveys(702 copies) through an online survey platform(Survey Star, Changsha Ranxing Science and Technology, Shanghai, China) to the participants, and the survey results were reviewed by two individuals. Eight copies of questionnaires were removed because of incomplete or contradictory in content.

Participants were asked about their work lines. The definition of work lines: the staff working in the isolation area was the first line; the staff working in fever clinic, outpatient and emergency department, laboratory were the second line; the staff who did not need to directly contact the COVID-19 patients, such as administrator and logistics supporter, were the third line.

\section{Statistical analysis}

The questionnaire results were input into Excel and analyzed by SPSS 24.0(IBM SPSS, Inc., Armonk, NY, USA). The data is described by the number of cases (percentage), median and interquartile range(IQR). The chi square test was used for categorical variables and the rank sum test was used for continuous variables. The risk factors of severe depression or panic disorder were analyzed by binary logistic regression test. The factors included in the multivariate model were selected based on a significance level of $p<0.1$ in the univariate analyses. The test with $P<0.05$ as the difference was statistically significant.

\section{Results}

In order to give a concise description of the development of the epidemic from January 15 to February 10, 2020 we presented the growth of cases in Figure 1(the data were available at: http://www.nhc.gov.cn/xcs/yqfkdt/gzbd_index.shtml;http://wsjkw.sh.gov.cn/yqtb/index.html). It showed the development trend of the COVID-19 epidemic in China between the end of January and the beginning of February 2020. During the survey period(February 8-February 10), 702 questionnaires were sent out, 694 (98.9\%) were received and qualified. Six hundreds and fifty-six female(94.5\%) participated in the questionnaire, and the highest proportion of people was 18-40 years(73\%). The proportion of nurse and physician was the highest, accounting for $45.1 \%$ and $22.3 \%$, respectively. The proportion of first-line personnel was $19.5 \%$, second-line personnel was $7.2 \%$, and thirdline was 73.5\%. The median score of PHQ-9 among all the staff was 1 (IQR,0-4), the median PDSS score was 2 (IQR,0-5). For the score of PHQ-9 among female staff was higher than that of male $(p=0.03)$; the score of nurse was much higher than that of physician $(p<0.0001)$ and staff with degree of undergraduate have much more score of PHQ-9 than that of postgraduate degree $(\mathrm{p}=0.03)$. For the score of PDSS, nurse was still much higher than that of physician $(\mathrm{p}<0.0001)$. Among the different work lines, the first-line scored the highest: PHQ-9 score was 4 (0-8); PDSS score was 4 (1-9), which were significantly higher than the second-line and third-line staff $(P<0.001)$. See more details in Table 1.

\section{Table 1. The demographic characteristics of people included in this analysis $(n=694)$}




\begin{tabular}{|c|c|c|c|c|c|}
\hline Demographic characteristics & Number[Percent] & PQH-9 (M, Q1-Q3) & P value & PDSS (M, Q1-Q3) & P value \\
\hline Gender & & & 0.031 & & 0.308 \\
\hline Male & $38(5.5 \%)$ & $0(0-2)$ & & $2(0-5)$ & \\
\hline Female & $656(94.5 \%)$ & $1(0-4)$ & & $2(0-5)$ & \\
\hline Age & & & 0.026 & & 0.063 \\
\hline $18-30$ years & $253(36.5 \%)$ & $1(0-4)$ & & $2(0-5)$ & \\
\hline $31-40$ years & $253(36.5 \%)$ & $1(0-4)$ & & $2(0-5)$ & \\
\hline $41-50$ years & $150(21.6 \%)$ & $0(0-3)$ & & $2(0-5)$ & \\
\hline$\geq 51$ years & $38(5.5 \%)$ & $0(0-1.25)$ & & $1(0-3)$ & \\
\hline Working years & & & 0.005 & & 0.015 \\
\hline $0-5$ years & $185(26.7 \%)$ & $1(0-3)$ & & $2(0-4)$ & \\
\hline $6-10$ years & $170(24.5 \%)$ & $1(0-5.25)$ & & $3(1-6)$ & \\
\hline $11-15$ years & $122(17.6 \%)$ & $1(0-4)$ & & $2(0-5)$ & \\
\hline 015 years & $217(31.3 \%)$ & $0(0-3)$ & & $2(0-5)$ & \\
\hline Occupations & & & $<0.0001$ & & $<0.0001$ \\
\hline Physician & $155(22.3 \%)$ & $0(0-3)$ & & $2(0-5)$ & \\
\hline Nurse & $313(45.1 \%)$ & $2(0-6)$ & & $3(1-6)$ & \\
\hline Technician and researcher & $101(14.6 \%)$ & $0(0-2)$ & & $2(0-4)$ & \\
\hline Administrator & $70(10.1 \%)$ & $0(0-2)$ & & $1.5(0-4)$ & \\
\hline Logistic and Supporter \& & $55(7.9 \%)$ & $0(0-1)$ & & $0(0-4)$ & \\
\hline Technical title & & & 0.004 & & 0.006 \\
\hline Junior & $454(65.4 \%)$ & $1(0-4)$ & & $2.5(0-5)$ & \\
\hline Intermediate & $170(24.5 \%)$ & $0(0-3)$ & & $2(0-4)$ & \\
\hline Senior & $70(10.1 \%)$ & $0(0-2)$ & & $1(0-4.25)$ & \\
\hline Educational level & & & 0.029 & & 0.063 \\
\hline$\leq$ undergraduate & $548(79.0 \%)$ & $1(0-4)$ & & $2(0-5)$ & \\
\hline$\geq$ postgraduate & $146(21.0 \%)$ & $0(0-2)$ & & $2(0-4)$ & \\
\hline Work lines & & & $<0.0001$ & & $<0.0001$ \\
\hline First line & $135(19.5 \%)$ & $4(0-8)$ & & $4(1-9)$ & \\
\hline Second line & $49(7.2 \%)$ & $1(0-3)$ & & $2(1-5)$ & \\
\hline Third line & $510(73.5 \%)$ & $0(0-3)$ & & $2(0-4)$ & \\
\hline
\end{tabular}

\&, means logistics personnel, equipment and technical support personnel.

The status of depression and panic disorder among different groups of participants

There were 143 (20.6\%) of them had depression, 39 (5.6\%) of them had severe depression status; 81 (11.7\%) of them had panic disorder, 47 (6.7\%) of people had severe panic disorder. The depression rate was $18 \%(27 / 155)$ in physician while it was $32 \%(100 / 313)$ in nurse. The panic disorder rate for physician was $6 \%(9 / 155)$ and $19 \%(59 / 313)$ for nurse. For the severity degree of depression status among different occupations, nurse was much severe than that of physician $(p<0.0001)$. For the severity of panic disorder, nurse still had much severe degree than that of physician $(p=0.0004)$. Among the different work lines, the first-line staff had the highest degree of depression and panic disorder than that of the non first-line $(P<0.001)$. See more in Table 2.

Table 2. The distribution of PHQ-9 and PDSS scores among participants with different characters 


\begin{tabular}{|c|c|c|c|c|c|c|c|c|c|c|c|c|}
\hline \multirow[t]{3}{*}{ Variables } & \multirow[t]{3}{*}{ Number } & \multicolumn{4}{|l|}{ PQH-9 } & \multirow{3}{*}{$\begin{array}{l}P \\
\text { value }\end{array}$} & \multicolumn{5}{|l|}{ PDSS } & \multirow{3}{*}{$\begin{array}{l}P \\
\text { value }\end{array}$} \\
\hline & & D0 & D1 & D2 & D3 & & P0 & $\mathrm{P} 1$ & P2 & P3 & & \\
\hline & & $\mathrm{N}(\%)$ & N (\%) & $\mathrm{N}(\%)$ & N (\%) & & N (\%) & $\mathrm{N}(\%)$ & N (\%) & $\mathrm{N}(\%)$ & N (\%) & \\
\hline Gender & & & & & & 0.204 & & & & & & 0.472 \\
\hline Male & 38 & $34(89)$ & $2(5)$ & $0(0)$ & $2(5)$ & & $27(71)$ & $10(26)$ & $0(0)$ & $1(3)$ & $0(0)$ & \\
\hline Female & 656 & $517(79)$ & $102(16)$ & $17(3)$ & $20(3)$ & & $409(62)$ & $167(25)$ & $34(5)$ & $36(5)$ & $10(2)$ & \\
\hline Age & & & & & & 0.278 & & & & & & 0.601 \\
\hline $18-30$ years & 253 & 194(77) & 42(17) & $8(3)$ & $9(4)$ & & 154(61) & $65(26)$ & $14(6)$ & $15(6)$ & $5(2)$ & \\
\hline $31-40$ years & 253 & 203(80) & $32(13)$ & $8(3)$ & $10(4)$ & & 155(61) & $69(27)$ & $12(5)$ & $13(5)$ & $4(2)$ & \\
\hline $41-50$ years & 150 & $119(79)$ & 27(18) & $1(1)$ & $3(2)$ & & $95(63)$ & $38(25)$ & $8(5)$ & $8(5)$ & $1(1)$ & \\
\hline$\geq 51$ years & 38 & $35(92)$ & $3(8)$ & $0(0)$ & $0(0)$ & & $32(84)$ & $5(13)$ & $0(0)$ & $1(3)$ & $0(0)$ & \\
\hline Working years & & & & & & 0.055 & & & & & & 0.139 \\
\hline $0-5$ years & 185 & 158(85) & 19(10) & $3(2)$ & $5(3)$ & & 121(65) & $47(25)$ & $5(3)$ & $11(6)$ & $1(1)$ & \\
\hline $6-10$ years & 170 & $120(71)$ & $36(21)$ & $6(4)$ & $8(5)$ & & $96(56)$ & $47(28)$ & $15(9)$ & $7(4)$ & $5(3)$ & \\
\hline $11-15$ years & 122 & $96(79)$ & 16(13) & $5(4)$ & $5(4)$ & & $75(61)$ & $32(26)$ & $4(3)$ & $8(7)$ & $3(2)$ & \\
\hline 015 years & 217 & 177(82) & $33(15)$ & $3(1)$ & $4(2)$ & & 144(66) & $51(24)$ & $10(5)$ & $11(5)$ & $1(0)$ & \\
\hline $\begin{array}{l}\text { Educational } \\
\text { level }\end{array}$ & & & & & & 0.056 & & & & & & 0.219 \\
\hline sundergraduate & 548 & $424(77)$ & $88(16)$ & $16(3)$ & $20(4)$ & & $336(61)$ & 141(26) & $29(5)$ & $32(6)$ & $10(2)$ & \\
\hline$\geq$ postgraduate & 146 & 127(87) & 16(11) & $1(1)$ & $2(1)$ & & $100(68)$ & $36(25)$ & $5(3)$ & $5(3)$ & $0(0)$ & \\
\hline Occupations & & & & & & $<0.0001$ & & & & & & 0.0004 \\
\hline Physician & 155 & 128(83) & 22(14) & $1(1)$ & $4(3)$ & & 103(66) & $43(28)$ & $3(2)$ & $5(3)$ & 1(1) & \\
\hline Nurse & 313 & 213(68) & $68(22)$ & $14(4)$ & $18(6)$ & & 169(54) & $85(27)$ & $22(7)$ & 29(9) & $8(3)$ & \\
\hline $\begin{array}{l}\text { Technician and } \\
\text { researcher }\end{array}$ & 101 & $94(93)$ & $7(7)$ & $0(0)$ & $0(0)$ & & $75(74)$ & $23(23)$ & $3(3)$ & $0(0)$ & $0(0)$ & \\
\hline Administrator & 70 & $62(89)$ & $6(9)$ & 2(3) & $0(0)$ & & $50(71)$ & 12(17) & $5(7)$ & 2(3) & 1(1) & \\
\hline Supporters[ & 55 & $54(98)$ & $1(2)$ & $0(0)$ & $0(0)$ & & $39(71)$ & $14(25)$ & $1(2)$ & $1(2)$ & $0(0)$ & \\
\hline Technical title & & & & & & 0.027 & & & & & & 0.163 \\
\hline Junior & 454 & $347(76)$ & 73(16) & $14(3)$ & $20(4)$ & & 270(59) & 123(27) & $23(5)$ & $29(6)$ & $9(2)$ & \\
\hline Intermediate & 170 & 142(84) & 25(15) & $3(2)$ & $0(0)$ & & 117(69) & $36(21)$ & $8(5)$ & $8(5)$ & $1(1)$ & \\
\hline Senior & 70 & 62(89) & $6(9)$ & $0(0)$ & $2(3)$ & & 49(70) & 18(26) & $3(4)$ & $0(0)$ & $0(0)$ & \\
\hline Work lines & & & & & & $<0.0001$ & & & & & & $<0.0001$ \\
\hline First line & 135 & 78(58) & $30(22)$ & $11(8)$ & 16(12) & & $62(46)$ & $35(26)$ & 14(10) & 16(12) & $8(6)$ & \\
\hline Second line & 49 & $40(82)$ & $7(14)$ & $1(2)$ & $1(2)$ & & $32(65)$ & 13(27) & $2(4)$ & $2(4)$ & $0(0)$ & \\
\hline Third line & 510 & 433(85) & 67(13) & $5(1)$ & $5(1)$ & & $342(67)$ & $129(25)$ & $18(4)$ & $19(4)$ & $2(0)$ & \\
\hline
\end{tabular}

PHQ-9: D0, normal; D1 for mild depression; D2 for moderate depression; D3 for severe depression. PDSS: P0, normal; P1, borderline; P2, slightly panic; $\mathrm{P} 3$, moderately panic; $\mathrm{P} 4$, markedly panic.

\Supporters, means logistics personnel, equipment and technical support personnel. 
By binary logistic regression test, univariate analysis showed that compared with staff with undergraduate, postgraduate staff had a lower risk of serious depression; participants with intermediate technical title had a lower risk than junior title; compared with physicians, nurses had a higher risk; the first-line workers had much more risk of severe depression than the third-line. After multivariate analysis, only found that the first-line workers had much more risk for severe depression than the third-line workers $(P<0.001)$. Other variables have no statistical significance, see Table 3 . For the first-line staff, the risk of severe depression was 6.6 times[(95\% Cl 3.1-14.3), $\mathrm{P}<0.001]$ higher than the non first-line(the combination of second line and third line).

Table 3. The risk factors for severe case of depression (PHQ-9 score $\geq 10$ )

\begin{tabular}{|c|c|c|c|c|c|c|}
\hline Variables & Category & Severe cases & Total cases $(\%)$ & $P$ valuel & AOR(95\%Cl) & $P$ value \\
\hline \multirow[t]{4}{*}{ Age } & $18-30$ years & 17 & $253 \otimes 7 \% \rrbracket$ & NA & & \\
\hline & $31-40$ years & 18 & $253 \rrbracket 7 \% \rrbracket$ & 0.861 & & \\
\hline & $41-50$ years & 4 & $150 \otimes 3 \% \bigotimes$ & 0.087 & & \\
\hline & $\geq 51$ years & 0 & $38 \bowtie 0 \% \rrbracket$ & 0.998 & & \\
\hline \multirow[t]{2}{*}{ Gender } & Male & 2 & $38 \otimes 5 \% \square$ & NA & & \\
\hline & Female & 37 & $656 \rrbracket 6 \% \rrbracket$ & 0.922 & & \\
\hline \multirow[t]{4}{*}{ Working years } & $0-5$ years & 8 & $185 \llbracket 4 \% \bigotimes$ & NA & & \\
\hline & $6-10$ years & 14 & $170 \llbracket 8 \% \rrbracket$ & 0.133 & & \\
\hline & $11-15$ years & 10 & $122 \llbracket 8 \% \bigotimes$ & 0.164 & & \\
\hline & \15 years & 7 & $217 \rrbracket 3 \% \rrbracket$ & 0.564 & & \\
\hline \multirow[t]{2}{*}{ Educational level } & $\leq$ undergraduate & 36 & $548 \otimes 7 \% \rrbracket$ & NA & 1 & NA \\
\hline & $\geq$ postgraduate & 3 & $146 \rrbracket 2 \% \rrbracket$ & 0.047 & $0.59(0.12-2.99)$ & 0.524 \\
\hline \multirow[t]{3}{*}{ Technical title } & Junior & 34 & $454 \rrbracket 7 \% \rrbracket$ & NA & 1 & NA \\
\hline & Intermediate & 3 & $170 \rrbracket 2 \% \rrbracket$ & 0.013 & 0.32(0.08-1.25) & 0.102 \\
\hline & Senior & 2 & $70 \otimes 3 \% \bigotimes$ & 0.171 & $0.56(0.09-3.50)$ & 0.537 \\
\hline \multirow[t]{5}{*}{ Occupations } & Physician & 5 & $155 \llbracket 3 \% \bigotimes$ & NA & 1 & NA \\
\hline & Nurse & 32 & $313 \rrbracket 10 \% \rrbracket$ & 0.012 & $0.94(0.20-4.38)$ & 0.937 \\
\hline & Technician and researcher & 0 & $101 \rrbracket 0 \% \bigotimes$ & 0.996 & $0.00(0.00-\infty)$ & 0.996 \\
\hline & Administrator & 2 & $70 \otimes 3 \% \rrbracket$ & 0.883 & $0.85(0.12-6.06)$ & 0.867 \\
\hline & Logistics and supporter & 0 & $55 \rrbracket 0 \% \rrbracket$ & 0.997 & $0.00(0.00-\infty)$ & 0.997 \\
\hline \multirow[t]{3}{*}{ Work lines } & First line & 27 & $135 \rrbracket 20 \% \rrbracket$ & NA & 1 & NA \\
\hline & Second line & 2 & $49 \llbracket 4 \% \rrbracket$ & 0.019 & $0.27(0.06-1.25)$ & 0.093 \\
\hline & Third line & 10 & $510 \rrbracket 2 \% \rrbracket$ & 0.000 & $0.12(0.06-0.27)$ & 0.000 \\
\hline
\end{tabular}

Q, refers to the $\mathrm{P}$ value for each category vs the reference. $\mathrm{AOR}$, Adjusted odds ratio; $\mathrm{Cl}$, confidence interval.

By univariate logistic regression test, the risk for severe panic disorder in nurse was much higher than that in physician, and second-line workers was significantly lower than that in first-line. After multivariate analysis, the risk for severe panic disorder in the first-line staff was significantly higher than that in the third line $(P=0.001)$. Other variables had no statistical significance, see Table 4. For the first-line personnel, the risk of serious panic is 2.6 fold $[(95 \% \mathrm{Cl} 1.4-4.9), \mathrm{P}=0.003]$ higher than that of the non first-line(the combination of the second line and third line).

Table 4. The risk factors for severe case of panic disorder (PDSS score $\geq 11$ ) 


\begin{tabular}{|c|c|c|c|c|c|c|}
\hline Variables & Category & Severe cases & Total cases (\%) & P valuel & $\mathrm{AOR}(95 \% \mathrm{Cl})$ & $P$ value \\
\hline \multirow[t]{4}{*}{ Age } & $18-30$ years & 20 & $253(8 \%)$ & NA & & \\
\hline & $31-40$ years & 17 & $253(7 \%)$ & 0.609 & & \\
\hline & $41-50$ years & 9 & $150(6 \%)$ & 0.476 & & \\
\hline & $\geq 51$ years & 1 & $38(3 \%)$ & 0.266 & & \\
\hline \multirow[t]{2}{*}{ Gender } & Male & 1 & $38(3 \%)$ & NA & & \\
\hline & Female & 46 & $656(7 \%)$ & 0.317 & & \\
\hline \multirow[t]{4}{*}{ Working years } & $0-5$ years & 12 & $185(6 \%)$ & NA & & \\
\hline & $6-10$ years & 12 & $170(7 \%)$ & 0.830 & & \\
\hline & $11-15$ years & 11 & $122(9 \%)$ & 0.412 & & \\
\hline & Q15 years & 12 & $217(6 \%)$ & 0.687 & & \\
\hline \multirow[t]{2}{*}{ Educational level } & sundergraduate & 42 & $548(8 \%)$ & NA & 1 & NA \\
\hline & $\geq$ postgraduate & 5 & $146(3 \%)$ & 0.078 & $1.23(0.33-4.49)$ & 0.759 \\
\hline \multirow[t]{3}{*}{ Technical title } & Junior & 38 & $454(8 \%)$ & NA & & \\
\hline & Intermediate & 9 & $170(5 \%)$ & 0.199 & & \\
\hline & Senior & 0 & $70(0 \%)$ & 0.997 & & \\
\hline \multirow[t]{5}{*}{ Occupations } & Physician & 6 & $155(4 \%)$ & NA & 1 & NA \\
\hline & Nurses & 37 & $313(12 \%)$ & 0.008 & $2.96(0.89-9.87)$ & 0.077 \\
\hline & Technician and researchers & 0 & $101(0 \%)$ & 0.996 & $0.00(0.00-\infty)$ & 0.996 \\
\hline & Administrators & 3 & $70(4 \%)$ & 0.883 & $1.52(0.32-7.32)$ & 0.600 \\
\hline & Logistics and supporters & 1 & $55(2 \%)$ & 0.477 & $0.68(0.07-6.71)$ & 0.740 \\
\hline \multirow[t]{3}{*}{ Work lines } & First line & 24 & $135(18 \%)$ & NA & 1 & NA \\
\hline & Second line & 2 & $49(4 \%)$ & 0.032 & $0.34(0.08-1.53)$ & 0.160 \\
\hline & Third line & 21 & $510(4 \%)$ & 0.000 & $0.32(0.17-0.63)$ & 0.001 \\
\hline
\end{tabular}

$\bigotimes$, refers to the $\mathrm{P}$ value for each category vs the reference. AOR, Adjusted odds ratio; $\mathrm{Cl}$, confidence interval.

\section{Discussion}

Since the end of January 2020, the number of confirmed cases, deaths related to COVID-19 has continued to escalate, with a sharp increase in the number of cumulative cases both in Shanghai and throughout the country[17,18]. Now, the epidemic of COVID-19 has posed a severe threat to the global public health and the prevention and control is full of challenge[19]. It is the background of the staff fighting for the epidemic in Shanghai public health clinical center. In any biological disaster, themes of fear, uncertainty, and stigmatisation are common[20]. As for the COVID-19, which is human-to-human transmissible, associated with high morbidity, and potentially fatal may intensify the perception of personal crisis[21]. The health workers may also experience fear of contagion and spreading the virus to their families, friends, or colleagues[20]. Therefore, the medical staff and their hospital colleagues have corresponding psychological pressure, which affects their own mental health[22].

Through this survey, 694(98.9\%) questionnaires were received. We found that most participants were female(95\%), were nurses(45\%), were aged 1840 years $(73 \%)$, were undergraduate $(65 \%)$, with a junior technical title( $79 \%)$. There were $143(21 \%)$ of them had depression, $39(6 \%)$ of them had severe depression status; 81 (12\%) of them had panic disorder, $47(7 \%)$ of people had severe panic disorder. The mental health status of health caregivers in a biological disaster is complicated. A study reported that, nearly $90 \%$ of health care workers who were in high-risk settings had psychological symptoms during the acute SARS outbreak[9]. Sources of distress may include feelings of vulnerability or loss of control and concerns about health of self, spread of virus, health of family and others, changes in work, and being isolated[23]. Challenges and stress can subsequently trigger common mental disorder, such as anxiety and depression[24].

Our findings also indicate that, not only the rate of depression or panic disorder but also the severity of depression or panic disorder among nurse were much higher than that of physician.Nurses treating patients with COVID-19 are likely exposed to the highest risk of infection because of their close, frequent contact with patients and working longer hours than usual[25]. Both the working pressure and physical exhaustion are risk factors 
for panic disorder[26]. During the SARS outbreak, a study[23] conducted among health care workers in emergency departments also showed that nurses were more likely to develop distress than physicians.

Among the different work lines, the front-line was an independent risk factor for worse mental health outcomes. This is consistent with the analysis published before[13,27]. For the health care worker in first line, they have to face the suffering and death of patients with COVID-19 and their risk of being infected is high while no effective vaccine or medicine for the virus. As for the rate(20\%) of depression among front-line staff in our study is lower than the figure(50\%) of health care workers fighting in Hubei province[13] which is the epicenter affected by COVID-19. In the initial stage of epidemic of COVID-19, predictable shortages of supplies and an increasing influx of suspected and confirmed cases of COVID-19 contribute to the pressures and concerns of health care workers in Wuhan[13], and they have been facing enormous pressure, including a high risk of infection and inadequate protection from contamination, overwork, patients with negative emotions, a lack of contact with their families, and exhaustion[27]. However, before the epidemic outbreak in Shanghai, local health committee and designated hospital had made full preparations for the prevention and control of COVID-19. The reserve of protective materials and medical equipment is sufficient, and the medical staff can provide backup for the designated hospital at any time. Therefore, the burden and severity of COVID-19 in Shanghai is much lower than that in Hubei Province, especially in Wuhan city. It's not surprising that participants in our study have a less serious mental health problem. However, compared with the general public, the mental health status of those front-line workers are affected severely and now the National Health Commission of China published a national guideline of psychological crisis intervention for COVID-19[27]. This will provide psychological protection for medical workers in China.

There are also some shortcomings in this study: in the survey, the marriage, family background and other public health emergency experiences of the participants were not obtained, and the background mental illness history, smoking and drinking habits of the participants were not found. Therefore, the potential factors behind the differences in scores of mental health assessment were not fully analyzed.

\section{Conclusions}

Many staff in the designated hospital for COVID-19 have mental health problems. Among them, first-line workers are a high-risk group with severe depression and panic disorder, and further psychological intervention is needed for them.

\section{List Of Abbreviations}

COVID-19: coronavirus disease 2019; PHQ-9: patients health questionnaire-9; PDSS: panic disorder severity scales; SARS: severe acute respiratory syndrome; WHO: world health organization; IQR: interquartile range.

\section{Declarations}

\section{Ethics approval and consent to participate}

The research protocols were approved by the Ethics Committee of Shanghai

Public Health Clinical Center. The written informed consent(electronic version) was obtained from all the study participants.

Consent for publication Not applicable.

Availability of data and materials All data generated or analysed during this study are included in this published article and its supplementary information files(S1 File).

Competing interests The authors declare that they have no competing interests.

Funding This study was supported by the grant of the research of novel regimen for COVID-19(The second batch of tackling of key scientific and technical problems launched by Shanghai Science and Technology Commission). The funders had no role in study design, data collection and analysis, decision to publish, or preparation of the manuscript.

Authors' contributors BFW, JJS, KW and HZL conceived and designed the study; BFW and JJS, FG, JC, LS, LYL, YJT collected the data. JJS, BFW and $\mathrm{KW}$ analyzed the data; JJS, BFW and KW, HZL interpreted the results; JJS and BFW wrote the first draft; JJS, BFW, KW and HZL contributed to the final version. All authors have read and approved the manuscript.

\section{Acknowledgments}

We give our cordial thanks to the colleagues of Shanghai Public Health Clinical Center who participated in our research.

\section{References}


1. van Doremalen N, Bushmaker T, Morris DH, Holbrook MG, Gamble A, Williamson BN, et al. Aerosol and Surface Stability of SARS-CoV-2 as Compared with SARS-CoV-1. N Engl J Med. 2020. doi: 10.1056/NEJMc2004973.

2. Zhu N, Zhang D, Wang W, Li X, Yang B, Song J, et al. A Novel Coronavirus from Patients with Pneumonia in China, 2019. N Engl J Med. 2020;382:727-33. doi: 10.1056/NEJMoa2001017.

3. Guo Y, Cao Q, Hong Z, Tan Y, Chen S, Jin H, et al. The origin, transmission and clinical therapies on coronavirus disease 2019 (COVID-19) outbreak - an update on the status. Military Medical Research. 2020;7. doi: 10.1186/s40779-020-00240-0.

4. Meo SA, Alhowikan AM, Al-Khlaiwi T, Meo IM, Halepoto DM, Iqbal M, et al. Novel coronavirus 2019-nCoV: prevalence, biological and clinical characteristics comparison with SARS-CoV and MERS-CoV. Eur Rev Med Pharmacol Sci. 2020;24:2012-9. doi: 10.26355/eurrev_202002_20379.

5. Backer JA, Klinkenberg D, Wallinga J. Incubation period of 2019 novel coronavirus (2019-nCoV) infections among travellers from Wuhan, China, 20-28 January 2020. Euro Surveill. 2020;25. doi: 10.2807/1560-7917.ES.2020.25.5.2000062.

6. Kucharski AJ, Russell TW, Diamond C, Liu Y, Edmunds J, Funk S, et al. Early dynamics of transmission and control of COVID-19: a mathematical modelling study. Lancet Infect Dis. 2020. doi: 10.1016/S1473-3099(20)30144-4

7. Lee A. Wuhan novel coronavirus (COVID-19): why global control is challenging? PUBLIC HEALTH. 2020;179:A1-2. doi: 10.1016/j.puhe.2020.02.001.

8. Yao H, Chen JH, Xu YF. Patients with mental health disorders in the COVID-19 epidemic. Lancet Psychiatry. 2020;7:e21. doi: 10.1016/S22150366(20)30090-0.

9. Chua SE, Cheung V, Cheung C, McAlonan GM, Wong JW, Cheung EP, et al. Psychological Effects of the SARS Outbreak in Hong Kong on HighRisk Health Care Workers. The Canadian Journal of Psychiatry. 2004;49:391-3. doi: 10.1177/070674370404900609.

10. Mok E, Chung BP, Chung JW, Wong TK. An exploratory study of nurses suffering from severe acute respiratory syndrome (SARS). International Journal of Nursing Practice. 2005;11:150-60. doi: 10.1111/j.1440-172X.2005.00520.x.

11. Wu P, Fang Y, Guan Z, Fan B, Kong J, Yao Z, et al. The psychological impact of the SARS epidemic on hospital employees in China: exposure, risk perception, and altruistic acceptance of risk. Can J Psychiatry. 2009;54:302-11. doi: 10.1177/070674370905400504.

12. Wang C, Pan R, Wan X, Tan Y, Xu L, Ho CS, et al. Immediate Psychological Responses and Associated Factors during the Initial Stage of the 2019 Coronavirus Disease (COVID-19) Epidemic among the General Population in China. International Journal of Environmental Research and Public Health. 2020;17:1729. doi: 10.3390/ijerph17051729.

13. Lai J, Ma S, Wang Y, Cai Z, Hu J, Wei N, et al. Factors Associated With Mental Health Outcomes Among Health Care Workers Exposed to Coronavirus Disease 2019. JAMA Netw Open. 2020;3:e203976. doi: 10.1001/jamanetworkopen.2020.3976.

14. Zhang YL, Liang W, Chen ZM, Zhang HM, Zhang JH, Weng XQ, et al. Validity and reliability of Patient Health Questionnaire-9 and Patient Health Questionnaire-2 to screen for depression among college students in China. Asia Pac Psychiatry. 2013;5:268-75. doi: 10.1111/appy.12103.

15. Zou Z, Huang Y, Wang J, He Y, Min W, Chen X, et al. Association of childhood trauma and panic symptom severity in panic disorder: Exploring the mediating role of alexithymia. JOURNAL OF AFFECTIVE DISORDERS. 2016;206:133-9. doi: 10.1016/j.jad.2016.07.027.

16. He Q, Mei Y, Liu Y, Yuan Z, Zhang J, Yan H, et al. Effects of Cytochrome P450 2C19 Genetic Polymorphisms on Responses to Escitalopram and Levels of Brain-Derived Neurotrophic Factor in Patients With Panic Disorder. JOURNAL OF CLINICAL PSYCHOPHARMACOLOGY. 2019;39:11723. doi: $10.1097 /$ JCP.0000000000001014.

17. Wang W, Tang J, Wei F. Updated understanding of the outbreak of 2019 novel coronavirus (2019-nCoV) in Wuhan, China. JOURNAL OF MEDICAL VIROLOGY. 2020;92:441-7. doi: 10.1002/jmv.25689.

18. Yang S, Cao P, Du P, Wu Z, Zhuang Z, Yang L, et al. Early estimation of the case fatality rate of COVID-19 in mainland China: a data-driven analysis. Ann Transl Med. 2020;8:128. doi: 10.21037/atm.2020.02.66.

19. Stratton SJ. COVID-19: Not a Simple Public Health Emergency. Prehospital and Disaster Medicine. 2020;35:119. doi: 10.1017/S1049023X2000031X.

20. Xiang YT, Yang Y, Li W, Zhang L, Zhang Q, Cheung T, et al. Timely mental health care for the 2019 novel coronavirus outbreak is urgently needed. Lancet Psychiatry. 2020;7:228-9. doi: 10.1016/S2215-0366(20)30046-8.

21. Heymann DL, Shindo N. COVID-19: what is next for public health? LANCET. 2020;395:542-5. doi: 10.1016/S0140-6736(20)30374-3.

22. Lee AM, Wong JG, McAlonan GM, Cheung V, Cheung C, Sham PC, et al. Stress and Psychological Distress among SARS Survivors 1 Year after the Outbreak. The Canadian Journal of Psychiatry. 2007;52:233-40. doi: 10.1177/070674370705200405.

23. Wong TW, Yau JK, Chan CL, Kwong RS, Ho SM, Lau CC, et al. The psychological impact of severe acute respiratory syndrome outbreak on healthcare workers in emergency departments and how they cope. European Journal of Emergency Medicine. 2005;12:13-8. doi: 10.1097/00063110-200502000-00005.

24. Dar KA, lqbal N, Mushtaq A. Intolerance of uncertainty, depression, and anxiety: Examining the indirect and moderating effects of worry. Asian J Psychiatr. 2017;29:129-33. doi: 10.1016/j.ajp.2017.04.017.

25. Chan S. Nurses Fighting Against Severe Acute Respiratory Syndrome (SARS) in Hong Kong. JOURNAL OF NURSING SCHOLARSHIP. 2003;35:209. doi: 10.1111/j.1547-5069.2003.00209.x.

Page 9/10 
26. Moreno-Peral P, Conejo-Cerón S, Motrico E, Rodríguez-Morejón A, Fernández A, García-Campayo J, et al. Risk factors for the onset of panic and generalised anxiety disorders in the general adult population: A systematic review of cohort studies. JOURNAL OF AFFECTIVE DISORDERS. 2014;168:337-48. doi: 10.1016/j.jad.2014.06.021.

27. Kang L, Li Y, Hu S, Chen M, Yang C, Yang BX, et al. The mental health of medical workers in Wuhan, China dealing with the 2019 novel coronavirus. Lancet Psychiatry. 2020;7:e14. doi: 10.1016/S2215-0366(20)30047-X.

\section{Figures}

\section{Figure 1. The development of the COVID-19 epidemic from January 15 to February 10, 2020 in China}

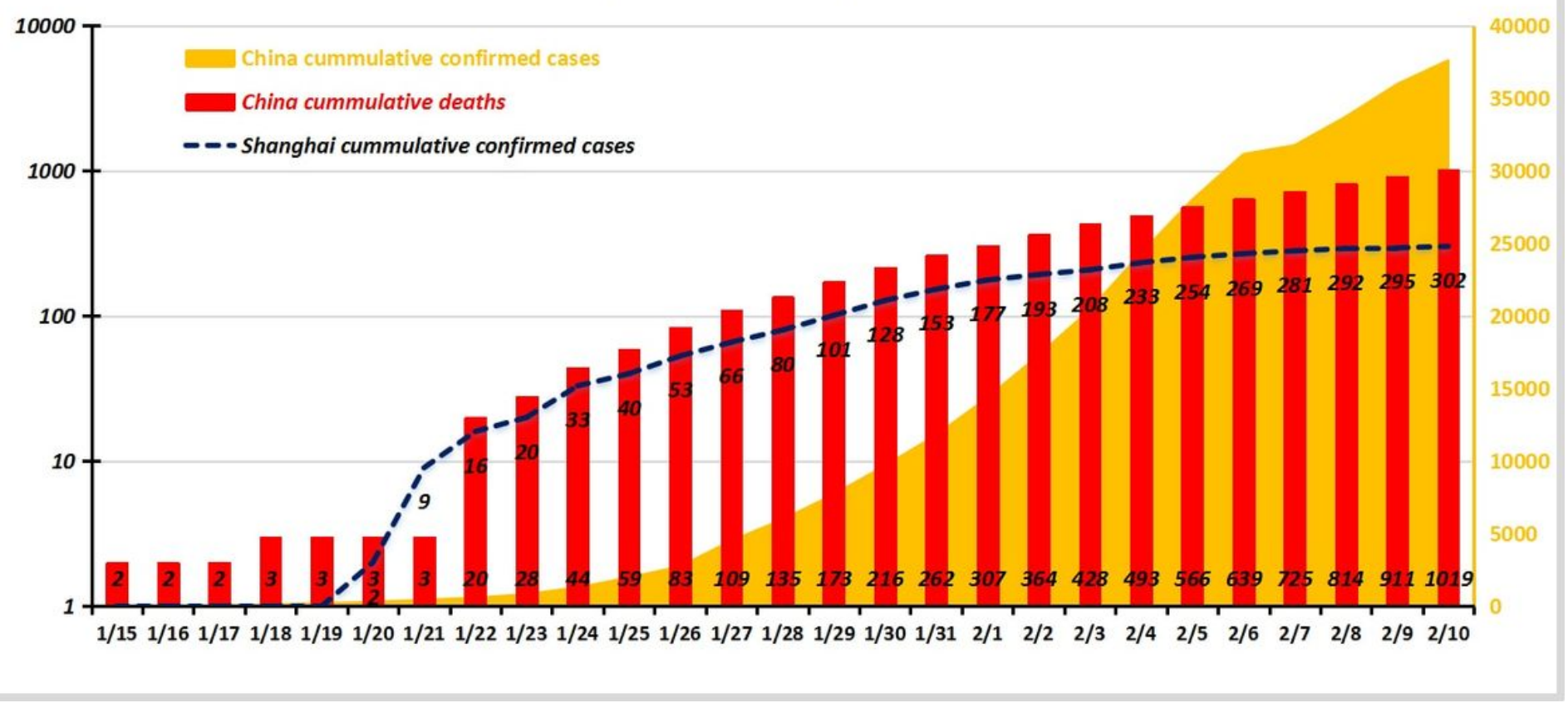

\section{Figure 1}

The development trend of the COVID-19 epidemic in China between the end of January and the beginning of February 2020. 